\title{
Salivary duct cyst: its frequency in a certain Japanese population group (Tohoku districts), with special reference to adenomatous proliferation of the epithelial lining
}

\author{
Yasunori Takeda and Hirotsugu Yamamoto ${ }^{\S}$ \\ Department of Oral Pathology, School of Dentistry, Iwate Medical University, Iwate 020-8505 \\ ${ }^{\S}$ Department of Pathology, Nihon University School of Dentistry at Matsudo, Chiba 271-8587
}

(Received 6 October 2000 and accepted 17 January 2001)

\begin{abstract}
It is reported in the European and American literature that salivary duct cysts constitute about $10 \%$ of all cysts of the salivary glands, although they appear to be rare in Japan. Between 1975 and 1999, only $3(0.5 \%)$ of 586 salivary gland cysts were diagnosed as salivary duct cysts at the Division of Clinical Pathology, Iwate Medical University Hospital. Histologically, two cases appeared as a unilocular lesion lined by double- and multi-layered epithelium. The other case showed marked, intraluminar and intramural adenomatous proliferation of the epithelial lining, suggesting that the lesion was a benign tumor. A review of the literature yielded only two cases of tumors arising in pre-existing salivary duct cysts. (J. Oral Sci. 43, 9 - 13, 2001)
\end{abstract}

Key word: salivary duct cyst; salivary gland cyst; epithelial lining; development of tumor.

\section{Introduction}

Acquired cysts of salivary glands are non-neoplastic, localized lesions of the duct system, and following three forms are distinguished: mucous cyst (extravasation type and retention type), ranula and salivary duct cyst. Of these, the most common lesion is the extravasation type of mucous cyst. Salivary duct cyst which, is believed to develop from marked cystic dilatation of a major salivary

Correspondence to Dr. Yasunori Takeda, Department of Oral Pathology, School of Dentistry, Iwate Medical University,

19-1 Uchimaru, Morioka, Iwate 020-8505, Japan

Phone: +81-19-651-5111 ext.3521

Fax: +81-19-621-3321

E-mail address: ytakeda@iwate-med.ac.jp gland duct (1-4), constitute about $10 \%$ of all cysts of the salivary glands in European countries and America (1-4). However, only a few cases of salivary duct cyst have been documented in Japan $(5,6)$. The purpose of this study was to examine tentative frequency of salivary duct cysts in a certain Japanese population group (Tohoku districts) and to report histological findings of these lesions.

\section{Materials and Methods}

Histological re-evaluation based on the 1991 WHO classification (2) was made on 586 salivary gland cysts filed at Division of Clinical Pathology, Iwate Medical University Hospital, Japan, between 1975 and 1999, and the results obtained was compared with that in Salivary Gland Register, Institute of Pathology of the University of Hamburg, Germany $(1,4)$. Clinical records and histological findings of cases diagnosed as salivary duct cyst were examined in detail, and haematoxylin and eosin-stained sections of each case were photographed.

\section{Results}

Histological classification of salivary gland cysts 586 cases of salivary gland cysts were filed at Division of Clinical Pathology, Iwate Medical University Hospital, Japan, between 1975 and 1999, and only 3 (0.5\%) were salivary duct cyst (Table 1). $79.7 \%$ of all salivary gland cysts were extravasation type of mucous cyst associated with minor salivary glands, and $19.3 \%$ were ranula. Remaining $1 \%$ was salivary duct cyst and retention type of mucous cyst. Most of the surgically resected specimens of these cases had been submitted from oral surgery clinics and otorhinology clinics, and a small numbers from general surgery clinics.

In the series of Seifert et al.(1) and Seifert (4), salivary 
duct cyst constituted about $10 \%$ of all salivary gland cysts. Up to about $70 \%$ of were extravasation type of mucous cyst associated with minor salivary glands, followed in decreasing order of frequency by retention type of mucous cyst (up to about $12 \%$ ), salivary duct cyst, lymphoepithelial cyst (up to about $6 \%$ ), ranula (up to about $5 \%$ ), dermoid cyst (up to $1.5 \%$ ), and dysgenetic polycystic disease (up to $0.4 \%$ ).

\section{Case presentation}

Case 1 was a 23 -year-old male who had an unilateral, painless swelling of the left submandibular area with several months-duration. The lesion was a rather well circumscribed, mobile, soft tissue mass with about $1 \mathrm{~cm}$ in diameter. The lesion was found to be unilocular epithelial cyst containing viscous fluid, and the cyst was separated from the salivary gland parenchyma by fibrous tissue (Fig. 1a). The epithelial lining was composed of double- or multi-layered columnar and/or cuboidal cells, with a smooth epithelial/fibrous tissue interface (Figs. 1b,c). Luminar epithelial cells had surface cilia, and some goblet cells were scattered in the epithelium. Slight and diffuse infiltration of small mononuclear cells in the fibrous tissue layer.
Case 2 was a 64 -year-old male with an unilateral, painless swelling of the left submandibular area of a few years-duration, and the swelling had appeared and disappeared a few times in that duration. The lesion was a rather well circumscribed, mobile, soft tissue mass with about $1.5 \mathrm{~cm}$ in diameter. Histological findings of the lesion were basically similar to those of Case 1 (Figs. 2a,b,c).

Case 3 was a 55-year-old male who complained of an unilateral, painless swelling of the left parotid area with 2 years-duration. The lesion was a rather well circumscribed, mobile, soft tissue mass with about $2 \mathrm{~cm}$ in diameter. The lesion was found to be multilocular epithelial cyst containing serous fluid, and the cyst was separated from the salivary gland parenchyma by fibrous tissue (Fig. 3a). The epithelial lining was basically composed of double- or multi-layered columnar and/or cuboidal cells. Furthermore, intraluminar and intramural, papillary proliferations of the epithelial lining, resulting in formation of adenomatous structures, were frequently seen (Figs. 3b,c). These adenomatous structures were composed of double- and/or multi-layered columnar and cuboidal cells with uniform in size and shape, and secretory materials were within the lumina (Fig. 4d). Some mucous

Table 1 Histologic classification of salivary gland cysts

Mucous cyst*

- Extravasation type

- Retention type

Salivary duct cyst**

Lymphoepithelial cyst

Ranula***

Dermoid cyst

Dysgenetic polycystic disease
Takeda \& Yamamoto (present)

Seifert et al. (1)

Seifert (4)

$\begin{array}{lllll} & 586(100.0 \%) & 478(100.0 \%) & 1,661(100.0 \%)\end{array}$

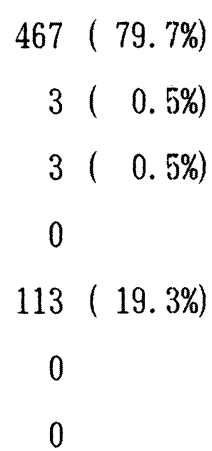

$467(79.7 \%)$

$312(65.3 \%)$

$59(12.3 \%)$

$51(10.7 \%)$

$29(6.1 \%)$

$25(5.2 \%)$

0

$2(0.4 \%)$
$1,171(70.5 \%)$

$175(10.5 \%)$

$160(9.6 \%)$

$79(4.8 \%)$

$49(2.9 \%)$

$24(1.5 \%)$

$3(0.2 \%)$

\footnotetext{
*Minor salivary gland lesions

** Retention type developed from major salivary gland ducts

***Extravasation type associated with sublingual glands
} 


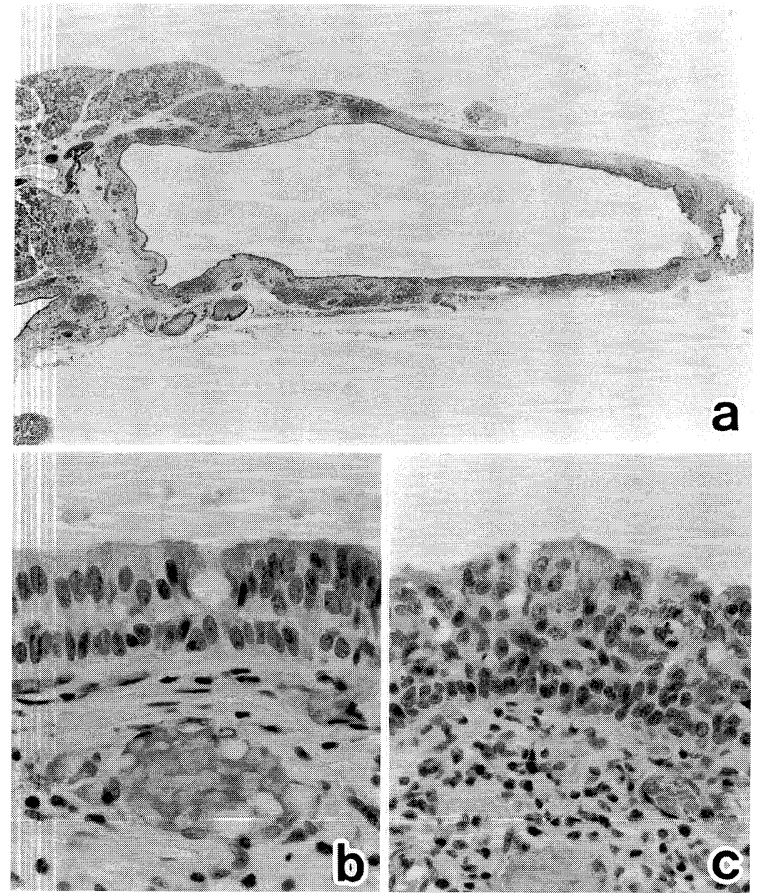

Fig. 1 Microscopic photographs of Case 1. (a) Whole cut view of unicystic lesion separated from the salivary gland parenchyma by fibrous tissue $(\mathrm{HE} ; \times 7)$. (b,c) The epithelial lining consisting of double- or multi-layered columnar and/or cuboidal cells, with a smooth epithelial/fibrous tissue interface $(\mathrm{HE} ; \times 200)$. Slight and diffuse infiltration of small mononuclear cells in the fibrous tissue layer.
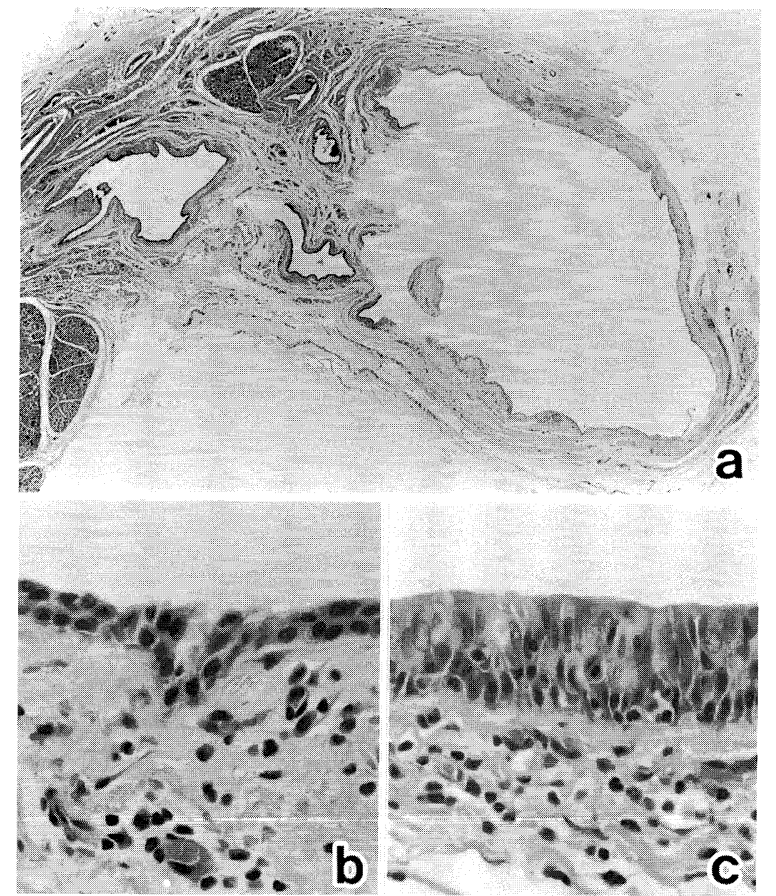

Fig. 2 Microscopic photographs of Case 2. (a) Whole cut view of unicystic lesion separated from the salivary gland parenchyma by fibrous tissue $(\mathrm{HE} ; \times 7)$. (b,c) The epithelial lining consisting of double- or multi-layered columnar and/or cuboidal cells, with a smooth epithelial/fibrous tissue interface $(\mathrm{HE} ; \times 200)$.

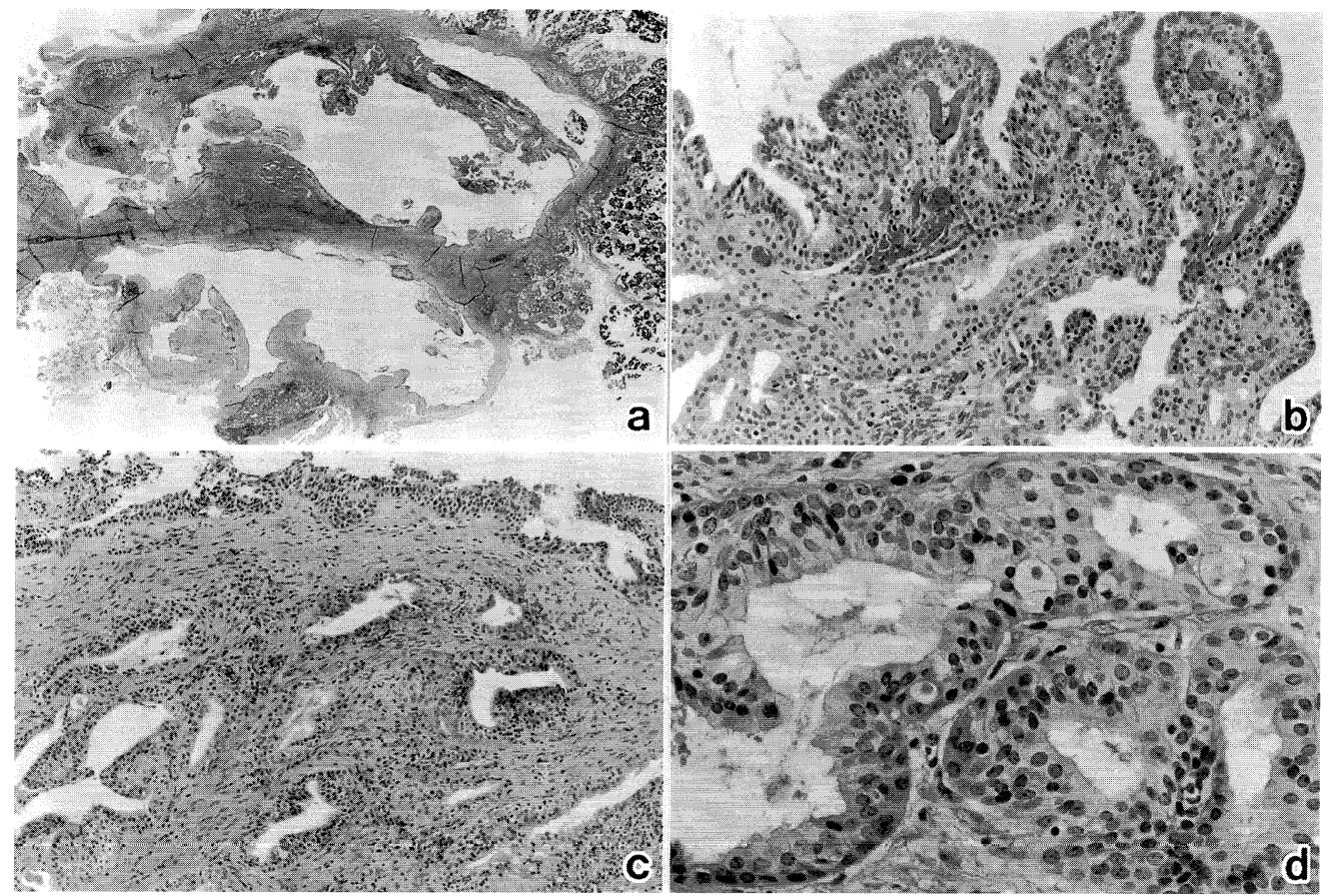

Fig. 3 Microscopic photographs of Case 3. (a) Whole cut view of polycystic lesion separated from the salivary gland parenchyma by fibrous tissue $(\mathrm{HE} ; \times 8)$. (b) Intraluminar, papillary proliferation of epithelial lining (HE; $\times 150)$. (c) Intramural proliferation of epithelial lining $(\mathrm{HE} ; \times 100)$. (d) Adenomatous structures of proliferating epithelial lining $(\mathrm{HE} ; \times 250)$. 
cells were scattered in the proliferating epithelium.

\section{Discussion}

Salivary duct cysts are acquired cysts that are believed to develop from marked cystic dilatation of a salivary gland duct, and ductal obstruction is thought to be a principal etiologic factor $(1,3)$. Although the obstruction that leads to the formation of these cysts may be due to a variety of causes, including caliculi, mucous plugs, postoperative or postinflammatory strictures, specific causes of obstruction are often not recognized. Three cases presented here showed no histological findings suggesting causes of ductal obstruction. Salivary duct cysts occur mainly in the parotid gland $(1,2,4)$, and Jensen (7) has described 152 cases of 166 salivary duct cysts occur in the parotid gland, 13 cases in the submandibular gland, and 1 case in the sublingual gland in the Armed Forces Institute of Pathology. There is no sex predilection. Children to older adults are affected, but most patients are over 30 to 40 years old. The cysts are unilateral, painless, compressible swelling ranging in size from 0.8 to $10 \mathrm{~cm}$, but the majority are 1 to $3 \mathrm{~cm}(1,3,7)$.

Salivary duct cyst is a common salivary gland lesion in European countries and America, and constitutes about $10 \%$ of all cysts of the salivary glands (1-4). However, only a few cases of salivary duct cyst have been documented in Japan $(5,6)$. In the present study of 586 cases of salivary gland cysts filed at Division of Clinical Pathology, Iwate Medical University Hospital, only $3(0.5 \%)$ were salivary duct cyst. Similar tendency was found in mucous cysts associated with minor salivary glands; retention type of mucous cysts was 10 to $12 \%$ of all salivary gland cysts in the series of Seifert et al. (1) and Seifert (4), and was $0.5 \%$ in the present study (Table 1). On the other hand, ranula was $19 \%$ of all salivary gland cysts in the present study, and was 3 to $5 \%$ in the series of Seifert et al. (1) and Seifert (4). The reason of such discrepancy between Morioka, Japan and Hamburg, Germany could not be understood.

The hypothesis has been discussed that distinct types of salivary gland cysts may be the early manifestation of a salivary gland tumor $(4,8)$, however, the review of the literature yields only 4 reports documenting tumors arising from pre-existing salivary gland cysts: a basal cell adenoma in lymphoepithelial cyst of the parotis (9), two mucoepidermoid carcinomas in retention type of mucous cysts associated with minor salivary gland (10), an adenocarcinoma in salivary duct cyst of the parotis (11), and a mucoepidermoid carcinoma in salivary duct cyst of the parotis (4). Case 3, presented here, was multilocular epithelial cyst, and showed intraluminar and intramural, papillary proliferations of the epithelial lining, resulting in formation of adenomatous structures. These adenomatous structures were composed of double- and/or multi-layered epithelial cells with uniform in size and shape, and secretory materials were within the lumina. Such marked, adenomatous proliferation of epithelial lining in salivary duct cyst has not been documented, though a few cases showing slight, focal hyperplasia of the epithelial lining with oncocytic melaplasia have been described $(5,6)$. Differential diagnosis of the present Case 3 had to primarily consider duct papillomas and papillary cyst adenoma. Duct papillomas occur in the minor salivary glands, and tumor cells of papillary cyst adenoma are similar to those of Warthin tumor but without the lymphoid element $(2,3)$. Epithelial cells of adenomatous proliferation in the present case did not show such characteristic.

In conclusion, salivary duct cyst is one of common salivary gland lesions in European countries and America, but rare in Japan. It has been hypothesized that the epithelial lining of salivary duct cyst may develop in benign or malignant tumors, but the review of the literature yields such cases are quite rare.

\section{References}

1. Seifert, G., Miehlke, A., Haubrich, J. and Chilla, R. (1986) Diseases of the salivary glands. Georg Thieme Verlag, Stuttgart, 91-100

2. Seifert, G. and Sobin, L.H. (1991) Histological typing of salivary gland tumours. 2nd ed., In International histological classification of tumours. World Health Organization ed., Springer-Verlag, Berlin, 36-37

3. Ellis, G.L. and Auclair, P.L. (1995) Tumors of the salivary glands. In Atlas of tumor pathology. 3rd series, Fascicle 17, Armed Forces Institute of Pathology, Washington D.C., 426-427

4. Seifert, G. (1996) Mucoepidermoid carcinoma in a salivary duct cyst of the parotid gland. Contribution to the development of tumours in salivary gland cysts. Pathol. Res. Pract. 192, 1211-1217

5. Takeda, Y., Suzuki, A. and Totsuka, M. (1989) Salivary duct cyst with adenomatous hyperplasia: report of a case. Nippon Koku Shindan Gakkai Zasshi 2, 158-161 (in Japanese)

6. Honma, Y., Ozono, S., Ito, Y and Kinoshita, Y. (2000) Salivary duct cyst in submandibular gland in young woman. Case report. Asian J. Oral Maxillofac. Surg. 12, 79-84

7. Jensen, J.L. (1991) Idiopathic diseases. In Major 
problems in pathology, Vol. 25, Surgical pathology of the salivary glands. Ellis, G.L., Auclair, P.L. and Gnepp, D.R. eds., W.B. Saunders Company, Philadelphia, 60-82

8. Southam, J.C. (1974) Retention mucoceles of the oral mucosa. J. Oral Pathol. 3, 197-202

9. Evans, C.S. and Goldman, R.L. (1986) Dermal analogue tumor arising in a lymphoepithelial cyst of the parotid gland. Arch. Pathol. Lab. Med.
$110,561-562$

10. Krueger, K., Younce, D., Najjar,T., Seldin, D., Koppelman, E. and Sansevere, J. (1994) Does mucoepidermoid carcinoma arise from cyst lining ? Congress of the International Association of Oral Pathologists, 35 (abstract)

11. Schwetschke, O., Zimmerer, A., Bosch, F.X. and Maier, H. (1994) Speichelgangzyste der Parotis und Adenokarzinom. HNO 42, 441-445 